\title{
Combination chemotherapy with docetaxel and carboplatin for elderly patients with endometrial cancer
}

\author{
HIROYUKI YOSHIDA, YUICHI IMAI and KEIICHI FUJIWARA \\ Department of Gynecologic Oncology, Saitama Medical University International Medical Center, \\ Hidaka, Saitama 350-1298, Japan
}

Received September 23, 2015; Accepted February 9, 2016

DOI: $10.3892 / \mathrm{mco} .2016 .781$

\begin{abstract}
Approximately half of all endometrial cancer cases are diagnosed in patients aged $>65$ years. The objective of this study was to compare the tolerability and effectiveness of combination chemotherapy with docetaxel and carboplatin between endometrial cancer patients older and younger than 65 years of age. Chemotherapy-naive patients with endometrial cancer were enrolled in this retrospective study between April, 2008 and March, 2015. The patients received docetaxel $\left(60 \mathrm{mg} / \mathrm{m}^{2}\right)$ and carboplatin (area under the curve of $6 \mathrm{mg}$ / $\mathrm{ml} / \mathrm{min}$ ) on day 1 of a 3 -week cycle. The tolerability and effectiveness of this regimen were analyzed. A total of 41 patients with endometrial cancer were enrolled in this study, of whom 26 $(63 \%)$ were aged $<65$ years and $15(37 \%)$ were aged $\geq 65$ years. There were no significant differences with regard to Eastern Cooperative Oncology Group performance status score and disease stage between the two groups. Patients aged $>65$ years were significantly more likely to have serous or clear-cell histology and high-grade tumors compared with the younger group $(\mathrm{P}=0.014$ and 0.012 , respectively). Although the number of chemotherapy cycles, cycle delays and treatment interruptions were comparable between older and younger patients, there was a trend toward more dose reductions in the older group $(\mathrm{P}=0.12)$. The incidence of hematological toxicities did not differ significantly between the two groups. The incidence of grade 3/4 diarrhea was significantly higher in the older group $(\mathrm{P}=0.014)$ and hypersensitivity was significantly more frequent in the younger group $(P=0.035)$. Patients aged $\geq 65$ years had equivalent response rates, progression-free survival and overall survival compared with those aged $<65$ years. These results suggest that combination chemotherapy with docetaxel and carboplatin was tolerable and effective for the treatment of elderly chemotherapy-naive patients with endometrial cancer.
\end{abstract}

Correspondence to: Dr Hiroyuki Yoshida, Department of Gynecologic Oncology, Saitama Medical University International Medical Center, 1397-1 Yamane, Hidaka, Saitama 350-1298, Japan E-mail: hiro_y@saitama-med.ac.jp

Key words: endometrial cancer, elderly, combination chemotherapy, docetaxel, carboplatin

\section{Introduction}

With the continued aging and increase in the life expectancy of the population worldwide, the age of patients with cancer is also expected to increase. Indeed, over $50 \%$ of solid cancers are diagnosed in patients aged $>65$ years, and the cancer incidence at ages $>65$ years is $\sim 10$ times higher compared with that in the younger population (1). Accordingly, the use of chemotherapeutic agents in elderly patients with cancer may also increase. However, there is not sufficient evidence of the tolerability and effectiveness of chemotherapeutic drugs among elderly patients with cancer. Moreover, treatment guidelines for elderly patients with cancer have not yet been established; this may be because these patients are often excluded from clinical trials, and also because the number of the clinical reports on such patients is insufficient. Even among the relatively few trials that include elderly patients, the majority are subset analyses of clinical trials. Therefore, determining the benefits of chemotherapy and doses of chemotherapeutic agents for elderly patients with cancer is often difficult in clinical practice.

The therapeutic problem for elderly patients originates from the fact that treatment response is affected by aging-related physiological changes that differ from those in younger patients; this is due to decreased drug absorption, liver metabolic capacity and renal excretory function being more common among elderly individuals. Additionally, several elderly patients with cancer have multiple chronic diseases, which may result in the use of a wide variety of drugs with consequent deleterious drug interactions and adverse events.

Endometrial cancer is the most common gynecological malignancy, with 52,630 new cases and 8,590 deaths in the United States reported in 2014 (2). Approximately 50\% of patients with endometrial cancer are older than 65 years (3), with a further increase anticipated in the future. Thus, determining the optimal treatment strategy for endometrial cancer in elderly patients will become increasingly more important. The majority of patients with endometrial cancer present with early-stage disease and may be cured with primary therapy; however, women with metastatic cancer or relapse have poor prognosis and require chemotherapy.

The Gynecologic Oncology Group 122 randomized study (GOG122 trial) compared the efficacy of radiotherapy to that of doxorubicin and cisplatin (AP therapy) for advanced endometrial cancer; the results showed a favorable prognosis 
for patients who underwent AP therapy (4). Furthermore, the results of the GOG177 trial that paclitaxel, doxorubicin and cisplatin (TAP therapy) was more effective compared with AP therapy, although the toxicity of TAP therapy was severe (5). Paclitaxel and carboplatin (TC therapy) exerted a therapeutic effect similar to that of TAP therapy, but with less toxicity (6). Moreover, a previous phase 2 trial found no differences in the effectiveness of docetaxel and cisplatin (DP), docetaxel and carboplatin (DC), and TC therapies for advanced endometrial cancer (7). As described above, the combination of an anthracycline-based drug, a platinum-containing drug and a taxane agent is used in endometrial cancer chemotherapy, with DC therapy being one of the most important treatment options $(8,9)$. However, there are few reports on the tolerability and effectiveness of DC therapy in elderly patients with cancer. Although there are some reports on DC therapy for elderly patients with other types of cancer (10-12), none of the previous reports have focused on endometrial cancer. Therefore, we evaluated the tolerability and effectiveness of DC chemotherapy for elderly patients with endometrial cancer.

\section{Patients and methods}

Patients. A total of 41 patients with endometrial cancer were enrolled in this retrospective study between April, 2008 and March, 2015. The study protocol was approved by the Ethics Committee of Saitama Medical University International Medical Center, and all the patients provided written informed consent prior to the procedure being performed. All the patients were staged according to the International Federation of Gynecology and Obstetrics (FIGO) staging system (13). Eligible patients had histologically proven endometrial cancer, an Eastern Cooperative Oncology Group (ECOG) performance status (PS) score of $\leq 2$ and adequate baseline hematological (absolute neutrophil count $\geq 500 / \mathrm{mm}^{3}$, platelet count $\geq 100,000 / \mathrm{mm}^{3}$ ), renal (serum creatinine $\leq 1.5 \mathrm{mg} / \mathrm{dl}$ ) and liver functions (serum bilirubin $\leq 1.5 \mathrm{mg} / \mathrm{dl}$ ). Patients were excluded if they had received previous chemotherapy for endometrial cancer or a concurrent malignancy.

Treatment. Docetaxel $\left(60 \mathrm{mg} / \mathrm{m}^{2}\right)$ was administered intravenously (i.v.) for $1 \mathrm{~h}$, followed by carboplatin administered i.v. for $1 \mathrm{~h}$. The dose of carboplatin was calculated according to the Calvert formula, with an area under the curve (AUC) of $6 \mathrm{mg} / \mathrm{ml} / \mathrm{min}$ using a calculated glomerular filtration rate from the Cockcroft-Gault formula (14). Docetaxel and carboplatin were administered on day 1 , and repeated every 3 weeks. Dexamethasone (16.5 mg i.v.) and palonosetron (0.75 mg i.v.) were administered as premedications prior to docetaxel. Treatment was continued until disease progression. Each chemotherapy cycle was only delivered if the absolute neutrophil and platelet counts on the day of treatment were at least 1,500 and $100,000 / \mathrm{mm}^{3}$, respectively. Otherwise, treatment was delayed until this level was achieved.

Toxicity and chemotherapy adjustments. Adverse events were graded at each cycle by study investigators according to the National Cancer Institute Common Terminology Criteria for Adverse Events, version 4.0 (15). Dose reductions were allowed at the investigator's discretion, depending on the onset of hematological toxicities, such as febrile neutropenia or grade 4 thrombocytopenia, or non-hematological toxicities $\geq$ grade 3 , excluding alopecia, nausea and vomiting. If necessary, the dose of both drugs was reduced as follows in the subsequent cycle: Docetaxel, $50 \mathrm{mg} / \mathrm{m}^{2}$ and carboplatin, AUC=5. Granulocyte colony-stimulating factor (G-CSF) and prophylactic antibiotics were permitted as clinically indicated in the presence of grade 4 neutropenia or febrile neutropenia.

Response evaluation. The treatment response was assessed every two or three cycles by computed tomography scans according to the Response Evaluation Criteria in Solid Tumors (16).

Statistical analysis. For this age-specific retrospective exploratory analysis, patients were dichotomized according to the age split of $<65$ or $\geq 65$ years at the time of chemotherapy administration. All the statistical tests were exploratory in nature. Categorical variables were evaluated by the Chi-square test or the Fisher's exact test, as appropriate for category size. Kaplan-Meier curves were produced for progression-free survival (PFS) and overall survival (OS) by age group. Both PFS and OS were calculated from the date of initial chemotherapy. The log-rank test was used to compare survival between the two groups. Statistical significance was set at $\mathrm{P}<0.05$.

\section{Results}

Patient characteristics. A total of 41 patients were enrolled in this retrospective study, of whom $(63 \%)$ were aged $<65$ years and $15(37 \%)$ were aged $\geq 65$ years. The patient and tumor characteristics were compared between the two groups (Table I). The median age in the younger group was 56.5 years (range, 36-64 years) and in the older group 70.0 years (range, 65-78 years). There were no significant differences in terms of PS score and FIGO stage between the two groups. Patients older than 65 years were significantly more likely to have serous or clear-cell histology and high-grade tumors compared with the younger group $(\mathrm{P}=0.014$ and 0.012 , respectively). Patients older than 65 years were also significantly more likely to have hypertension $(\mathrm{P}=0.0017)$. There were no significant differences between the two groups in the prevalence of diabetes mellitus, cardiac disease or pulmonary disease.

Feasibility. The feasibility of DC therapy was analyzed (Table II). The number of cycles received did not differ between the two groups. Dose reductions were required in $6(23 \%)$ patients from the younger group and 7 (46\%) from the older group. There was a trend toward more dose reductions among patients aged $>65$ years $(\mathrm{P}=0.12)$, but the difference was not significant. Hematological toxicity was the most common reason for dose reduction in the older group (26\%), whereas hematological as well as non-hematological toxicities were responsible for dose reductions in the younger group. There were no significant differences in cycle delays or reasons for cycle delays between the groups. The occurrence rate of treatment interruption also did not differ significantly between the groups. Progressive disease was the most common reason for treatment interruption in the younger (19\%) as well as in the older group (26\%). There was no significant difference in the number of patients 
Table I. Baseline characteristics of the patients.

\begin{tabular}{|c|c|c|c|}
\hline Characteristics & $\begin{array}{c}<65 \text { years, } \mathrm{n}(\%) \\
(\mathrm{n}=26)\end{array}$ & $\begin{array}{c}\geq 65 \text { years, } \mathrm{n}(\%) \\
(\mathrm{n}=15)\end{array}$ & P-value \\
\hline ECOG PS & & & 0.11 \\
\hline 0 & $24(92)$ & $10(67)$ & \\
\hline 1 & $1(4)$ & $3(20)$ & \\
\hline 2 & $1(4)$ & $2(13)$ & \\
\hline Stage & & & 0.39 \\
\hline IA & $1(4)$ & $1(7)$ & \\
\hline IB & $7(27)$ & $3(20)$ & \\
\hline II & $7(27)$ & $1(7)$ & \\
\hline IIIA/B & $2(8)$ & $2(13)$ & \\
\hline IIIC1 & $2(8)$ & $0(0)$ & \\
\hline IIIC2 & $2(8)$ & $1(7)$ & \\
\hline IVB & $5(19)$ & $7(46)$ & \\
\hline Histology & & & 0.014 \\
\hline Endometrioid & $25(96)$ & $9(60)$ & \\
\hline Serous & $0(0)$ & $3(20)$ & \\
\hline Clear cell & $0(0)$ & $1(7)$ & \\
\hline Mixed & $0(0)$ & $2(13)$ & \\
\hline Undifferentiated & $1(4)$ & $0(0)$ & \\
\hline Grade & & & 0.012 \\
\hline 1 & $13(50)$ & $4(26)$ & \\
\hline 2 & $9(34)$ & $2(13)$ & \\
\hline 3 & $4(16)$ & $9(60)$ & \\
\hline \multicolumn{4}{|l|}{ Comorbidities } \\
\hline Hypertension & $4(16)$ & $10(67)$ & 0.0017 \\
\hline Diabetes mellitus & $7(27)$ & $3(20)$ & 0.72 \\
\hline Cardiac disease & $1(4)$ & $2(13)$ & 0.54 \\
\hline Pulmonary disease & $3(12)$ & $1(7)$ & $>0.99$ \\
\hline
\end{tabular}

ECOG PS, Eastern Cooperative Oncology Group performance status.

who received G-CSF between the two groups. G-CSF was used in 33 and $19 \%$ of the older and younger patients, respectively.

Adverse effects. The incidence of hematological toxicities, such as anemia, leukopenia, neutropenia and thrombocytopenia, did not differ significantly between the two groups (Table III). The most common grade 3/4 hematological toxicity was neutropenia, occurring in $77 \%$ of the younger patients and $80 \%$ of the older patients. The incidence of non-hematological toxicities did not differ significantly between the groups with regard to nausea, vomiting, neurotoxicity and myalgia (Table IV). The incidence of grade 3/4 diarrhea was significantly higher in the older group compared with that in the younger group $(\mathrm{P}=0.014)$. Hypersensitivity was significantly more frequent in the younger group $(\mathrm{P}=0.035)$.

Response and survival. Of the 8 patients with target lesions assessable for response in the younger group, 4 achieved a partial response. Of the 7 patients with target lesions assessable for response in the older group, 1 achieved a complete response and 2 a partial response (Table V). The tumor response to DC therapy did not differ significantly between the two groups. There was no significant difference in PFS (Fig. 1, P=0.57) or OS (Fig. 2, $\mathrm{P}=0.18$ ) between the two groups.

\section{Discussion}

As the aging population continues to grow, there is a consequent increase in the life expectancy worldwide. Thus, the incidences of diseases that affect the elderly, such as cancer, are also expected to increase. Therefore, the use of chemotherapeutic agents for elderly patients with cancer may also increase. Nonetheless, there is no definitive evidence of the tolerability and effectiveness of chemotherapeutic drugs among elderly patients with cancer. Previous reports have concluded that elderly patients experience more chemotherapy-related adverse events compared with younger patients, due to the deteriorating organ function and poor nutritional status. For example, a limited number of studies reported an increased incidence of myelosuppression due to chemotherapy, and hypertension as a result of bevacizumab therapy in elderly patients with colon cancer compared with younger patients $(17,18)$. Additionally, 
Table II. Number of cycles and feasibility of chemotherapy.

\begin{tabular}{|c|c|c|c|}
\hline Variables & $\begin{array}{c}<65 \text { years, } n(\%) \\
(n=26)\end{array}$ & $\begin{array}{c}\geq 65 \text { years, } n(\%) \\
(n=15)\end{array}$ & P-value \\
\hline Number of cycles & & & 0.33 \\
\hline $1-3$ & $8(30)$ & $6(40)$ & \\
\hline $4-6$ & $16(61)$ & $6(40)$ & \\
\hline$>6$ & $2(8)$ & $3(20)$ & \\
\hline Dose reduction & $6(23)$ & $7(46)$ & 0.12 \\
\hline \multicolumn{4}{|l|}{ Reasons } \\
\hline Hematological toxicity & $3(11)$ & $4(26)$ & \\
\hline Non-hematological toxicity & $3(11)$ & $1(7)$ & \\
\hline Others & $0(0)$ & $2(13)$ & \\
\hline Cycle delay & $7(27)$ & $5(33)$ & 0.73 \\
\hline \multicolumn{4}{|l|}{ Reasons } \\
\hline Hematological toxicity & $7(27)$ & $3(20)$ & \\
\hline Non-hematological toxicity & $0(0)$ & $1(7)$ & \\
\hline Others & $0(0)$ & $1(7)$ & \\
\hline Treatment interruption & $12(46)$ & $9(60)$ & 0.39 \\
\hline \multicolumn{4}{|l|}{ Reasons } \\
\hline Toxicity & $4(15)$ & $1(7)$ & \\
\hline Progressive disease & $5(19)$ & $4(26)$ & \\
\hline Patient's withdrawal & $3(11)$ & $3(20)$ & \\
\hline Others & $0(0)$ & $1(7)$ & \\
\hline
\end{tabular}

Table III. Worst degree of hematological toxicities by patient according to NCI-CTC 4.0.

\begin{tabular}{|c|c|c|c|c|c|c|}
\hline \multirow[b]{2}{*}{ Toxicities } & \multicolumn{3}{|c|}{ All grades } & \multicolumn{3}{|c|}{ Grade $\geq 3$} \\
\hline & $\begin{array}{c}<65 \text { years, } n(\%) \\
(n=26)\end{array}$ & $\begin{array}{c}\geq 65 \text { years, } n(\%) \\
(n=15)\end{array}$ & P-value & $\begin{array}{c}<65 \text { years, } n(\%) \\
(n=26)\end{array}$ & $\begin{array}{c}\geq 65 \text { years, } n(\%) \\
(n=15)\end{array}$ & P-value \\
\hline Anemia & $23(88)$ & $14(88)$ & $>0.99$ & $9(35)$ & $6(40)$ & 0.73 \\
\hline Leukopenia & $21(81)$ & $13(87)$ & 0.99 & $15(58)$ & $11(73)$ & 0.50 \\
\hline Neutropenia & $21(81)$ & $13(87)$ & $>0.99$ & $20(77)$ & $12(80)$ & $>0.99$ \\
\hline Thrombocytopenia & $19(73)$ & $10(67)$ & 0.73 & $3(12)$ & $0(0)$ & 0.29 \\
\hline Febrile neutropenia & $2(8)$ & $3(20)$ & 0.34 & $2(8)$ & $3(20)$ & 0.34 \\
\hline
\end{tabular}

NCI-CTC 4.0, National Cancer Institute Common Terminology Criteria for Adverse Events, version 4.0.

cardiac toxicity and treatment-related deaths with anthracycline-based drugs were more common among elderly patients with breast cancer compared with younger patients $(19,20)$.

With regard to elderly patients with gynecological cancer, a previous study reported that the completion rate of chemotherapy was reduced in elderly patients with ovarian cancer (aged $\geq 65$ years) with $>2$ comorbidities (21). Additionally, compared with younger patients, the disease is generally more advanced at diagnosis and tends to progress more quickly in elderly patients with ovarian cancer aged $>70$ years. This results in a higher risk of mortality and a significantly lower 5-year survival rate among these patients (22). By contrast, in a clinical trial by Eisenhauer et al, there was no difference in the frequency of dose reduction, treatment interruption, response rate, or prognosis among patients aged $\geq 65$ or $<65$ years who received combination chemotherapy with a platinum-containing drug and a taxane agent as an initial postoperative chemotherapy for advanced ovarian cancer (23).

Only few studies have reported on the tolerability and effectiveness of DC therapy in elderly patients with cancer. A comparison of patients with cancer older and younger than 65 years of age treated with docetaxel revealed no differences in docetaxel clearance, incidence of grade 4 neutropenia, or incidence of febrile neutropenia between the two groups (24). Conversely, in a clinical trial where docetaxel was administered to prostate cancer patients older than 75 years, the chemotherapy regimen was modified (e.g., dose reduction) in $46 \%$ of the patients (25). Additionally, in a clinical trial of DC therapy 
Table IV. Worst degree of non-hematological toxicities by patient according to NCI-CTC 4.0.

\begin{tabular}{|c|c|c|c|c|c|c|}
\hline \multirow[b]{2}{*}{ Toxicities } & \multicolumn{3}{|c|}{ All grades } & \multicolumn{3}{|c|}{ Grade $\geq 3$} \\
\hline & $\begin{array}{c}<65 \text { years, } n(\%) \\
(n=26)\end{array}$ & $\begin{array}{c}\geq 65 \text { years, } n(\%) \\
(n=15)\end{array}$ & P-value & $\begin{array}{c}<65 \text { years, } n(\%) \\
(n=26)\end{array}$ & $\begin{array}{c}\geq 65 \text { years, } n(\%) \\
(n=15)\end{array}$ & P-value \\
\hline Nausea & $13(50)$ & $11(73)$ & 0.20 & $2(8)$ & $0(0)$ & 0.52 \\
\hline Vomiting & $6(23)$ & $4(27)$ & $>0.99$ & $0(0)$ & $0(0)$ & $>0.99$ \\
\hline Diarrhea & $5(19)$ & $7(47)$ & 0.083 & $0(0)$ & $4(27)$ & 0.014 \\
\hline Neurotoxicity & $14(54)$ & $9(60)$ & 0.70 & $1(4)$ & $1(7)$ & $>0.99$ \\
\hline Myalgia & $7(27)$ & $2(13)$ & 0.45 & $1(4)$ & $0(0)$ & $>0.99$ \\
\hline Hypersensitivity & $7(27)$ & $0(0)$ & 0.035 & $0(0)$ & $0(0)$ & $>0.99$ \\
\hline
\end{tabular}

NCI-CTC 4.0, National Cancer Institute Common Terminology Criteria for Adverse Events, version 4.0.

Table V. Response to chemotherapy.

\begin{tabular}{lcc}
\hline Type of response & $\begin{array}{c}<6 \text { years, }(\%) \\
(\mathrm{n}=26)\end{array}$ & $\begin{array}{c}\geq 65 \text { years, } \mathrm{n}(\%) \\
(\mathrm{n}=15)\end{array}$ \\
\hline Complete response & $0(0)$ & $1(7)$ \\
Partial response & $4(15)$ & $2(13)$ \\
Stable disease & $2(8)$ & $1(7)$ \\
Progressive disease & $2(8)$ & $3(20)$ \\
Not evaluable disease & $18(69)$ & $8(53)$ \\
\hline
\end{tabular}

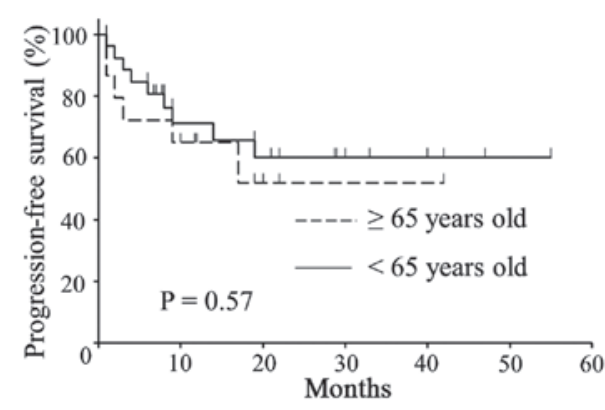

Figure 1. Kaplan-Meier survival analysis showing no significant difference in progression-free survival between elderly (dashed line; $\mathrm{n}=15$ ) and younger (solid line; $\mathrm{n}=26)$ patients $(\mathrm{P}=0.57$; log-rank test).

for non-small-cell lung cancer, subgroup analyses of patients aged $>65$ years revealed that $86 \%$ of the patients developed grade $\geq 3$ neutropenia, the incidence of febrile neutropenia was $7 \%$, and the incidence of grade $\geq 3$ non-hematological toxicities was $<17.5 \%(26)$.

In this trial, there was no difference in the frequency of treatment delay or interruption between older and younger patients with endometrial cancer who received DC therapy. The frequency of dose reduction tended to be higher among older patients (46\% in older and $23 \%$ in younger patients), but this difference was not significant. Hematological toxicities were the main cause of dose reductions in older patients. In younger patients, hematological and non-hematological toxicities were equally responsible for the dose reductions. However, no difference in the incidence of hematological toxicities was observed

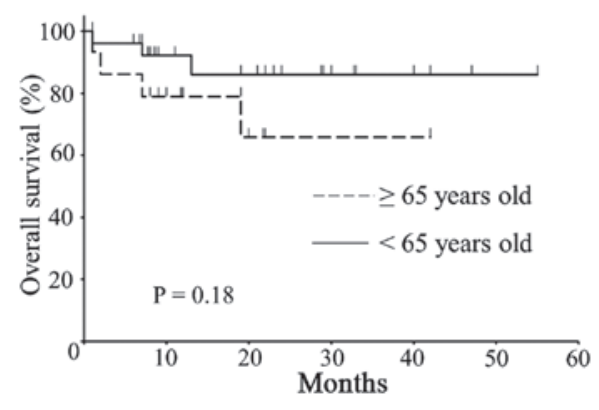

Figure 2. Kaplan-Meier survival analysis showing no significant difference in overall survival between elderly (dashed line; $\mathrm{n}=15$ ) and younger (solid line; $\mathrm{n}=26)$ patients $(\mathrm{P}=0.18$; log-rank test $)$.

between older and younger patients. Among patients who developed grade $\geq 3$ hematological toxicities, neutropenia was the most frequent complication in both age groups. As regards non-hematological toxicities, the incidence of grade $\geq 3$ diarrhea was significantly higher among older patients (0 vs. $27 \%$, $\mathrm{P}=0.014)$, whereas the incidence of hypersensitivity was significantly higher among younger patients (27 vs. $0 \%, \mathrm{P}=0.035)$. In any case, in the older and younger groups, DC therapy-related hematological and non-hematological toxicities were manageable, and DC therapy was generally well-tolerated in both groups, with acceptable effectiveness; however, it was difficult to evaluate the effectiveness of DC therapy due to the rarity of assessable lesions. There were no significant differences in prognosis between the two groups. Therefore, we consider DC therapy to have an acceptable toxicity profile and efficacy in 
endometrial cancer patients aged $>65$ years, when compared with younger patients. However, as this study included relatively few cases, a larger prospective study is required in the future.

Fader et al compared the effectiveness and toxicity of TC therapy in elderly patients with ovarian cancer aged $\geq 70$ years, who were subdivided into a standard-dose and a dose-reduction group (27). Carboplatin (AUC=5-6) and paclitaxel $\left(175 \mathrm{mg} / \mathrm{m}^{2}\right)$ were administered to patients in the standard-dose group, whereas carboplatin $(\mathrm{AUC}=4-5)$ and paclitaxel $\left(135 \mathrm{mg} / \mathrm{m}^{2}\right)$ were administered to those in the dose-reduction group. The results revealed a significantly lower frequency of neutropenia in the dose-reduction group and no significant differences in the response rate or prognosis between the two groups, suggesting that chemotherapy may be safely administered without becoming less effective, even when reducing dosage for elderly patients. Furthermore, in this study, dose reduction tended to be more frequent among older patients; however, there were no differences in the response rate or prognosis between the two age groups. Thus, the optimal dose for elderly patients may be lower than the standard dose.

In our aging society, the number of elderly patients receiving chemotherapy is expected to increase in the future. Determining an appropriate chemotherapy regimen and the optimal dose is crucial for elderly patients due to their vulnerability. However, there are few clearly determined indices for evaluating the vulnerability of elderly cancer patients and estimating the optimal doses of chemotherapeutic agents to be administered to such patients. Further studies are required to design safe and effective chemotherapeutic regimens to elderly cancer patients.

\section{References}

1. Monson K, Litvak DA and Bold RJ: Surgery in the aged population: Surgical oncology. Arch Surg 138: 1061-1067, 2003.

2. Siegel R, Ma J, Zou Z and Jemal A: Cancer statistics, 2014. CA Cancer J Clin 64: 9-29, 2014.

3. Platz CE and Benda JA: Female genital tract cancer. Cancer 75: 270-294, 1995

4. Randall ME, Filiaci VL, Muss H, Spirtos NM, Mannel RS, Fowler J, Thigpen JT and Benda JA; Gynecologic Oncology Group Study: Randomized phase III trial of whole-abdominal irradiation versus doxorubicin and cisplatin chemotherapy in advanced endometrial carcinoma: A Gynecologic Oncology Group study. J Clin Oncol 24: 36-44, 2006.

5. Fleming GF, Brunetto VL, Cella D, Look KY, Reid GC, Munkarah AR, Kline R, Burger RA, Goodman A and Burks RT: Phase III trial of doxorubicin plus cisplatin with or without paclitaxe plus filgrastim in advanced endometrial carcinoma: A gynecologic oncology group study. J Clin Oncol 22: 2159-2166, 2004.

6. Miller D, Fillaci V, Fleming G, Mannel R, Cohn D, Matsumoto T, Tewari K, DiSilvestro P, Pearl M and Zaino R: Randomized phase III noninferiority trial of first-line chemotherapy for metastatic or recurrent endometrial carcinoma: A Gynecologic Oncology Group study. Gynecol Oncol 125: 771-773, 2012.

7. Nomura H, Aoki D, Takahashi F, Katsumata N, Watanabe Y, Konishi I, Jobo T, Hatae M, Hiura M and Yaegashi N: Randomized phase II study comparing docetaxel plus cisplatin, docetaxel plus carboplatin, and paclitaxel plus carboplatin in patients with advanced or recurrent endometrial carcinoma: A Japanese Gynecologic Oncology Group study (JGOG2041). Ann Oncol 22: 636-642, 2011.

8. ScribnerDR Jr, Puls LE and Gold MA: A phase II evaluation of docetaxel and carboplatin followed by tumor volume directed pelvic plus or minus paraaortic irradiation for stage III endometrial cancer. Gynecol Oncol 125: 388-393, 2012.

9. Geller MA, Ivy JJ, Ghebre R, DownsLS Jr, Judson PL, Carson LF, Jonson AL, Dusenbery K, Vogel RI, Boente MP, et al: A phase II trial of carboplatin and docetaxel followed by radiotherapy given in a 'sandwich' method for stage III, IV and recurrent endometrial cancer. Gynecol Oncol 121: 112-117, 2011.
10. Yoshimura N, Kudoh S, Kimura T, Mitsuoka S, Kyoh S, Tochino Y, Asai K, Kodama T, Ichimaru Y, Yana T and Hirata K: Phase II study of docetaxel and carboplatin in elderly patients with advanced non-small cell lung cancer. J Thorac Oncol 4: 371-375, 2009.

11. Kim HJ, Kim TG, Lee HJ, Kim JH, Lim BH, Seo JW, Kang EM, Lee BU, Ahn YM, Roh YH, et al: A phase II study of combination chemotherapy with docetaxel and carboplatin for elderly patients with advanced non-small cell lung cancer. Lung Cancer 68: 248-252, 2010.

12. Kurt E, Cubukcu E, Karabulut B, Olmez OF, Kurt M, Avci N, Ozdemir F, Tunali D, Evrensel T and Manavoglu O: A multi-institutional evaluation of carboplatin plus docetaxel regimen in elderly patients with advanced gastric cancer. J BUON 18: 147-153, 2013.

13. Pecorelli S: Revised FIGO staging for carcinoma of the vulva, cervix, and endometrium. Int J Gynaecol Obstet 105: 103-104, 2009.

14. Cockcroft DW and Gault MH: Prediction of clearance from serum creatinine. Nephron 16: 31-41, 1976.

15. National Cancer Institute: Common Terminology Criteria for Adverse Events (CTCAE) version 4.0. http://ctep.cancer.gov/ protocolDevelopment/electronic_applications/ctc.htm\#ctc_40. Accessed June 21, 2015.

16. Therasse P, Arbuck SG, Eisenhauer EA, Wanders J, Kaplan RS, Rubinstein L, Verweij J, Van Glabbeke M, van Oosterom AT, Christian MC and Gwyther SG: New guidelines to evaluate the response to treatment in solid tumors. European Organization for Research and Treatment of Cancer, National Cancer Institute of the United States, National Cancer Institute of Canada. J Natl Cancer Inst 92: 205-216, 2000.

17. Goldberg RM, Tabah-Fisch I, Bleiberg H, de Gramont A, Tournigand C, Andre T, Rothenberg ML, Green E and Sargent DJ: Pooled analysis of safety and efficacy of oxaliplatin plus fluorouracil/leucovorin administered bimonthly in elderly patients with colorectal cancer. J Clin Oncol 24: 4085-4091, 2006.

18. Kabbinavar FF, Schulz J, McCleod M, Patel T, Hamm JT, Hecht JR, Mass R, Perrou B, Nelson B and Novotny WF: Addition of bevacizumab to bolus fluorouracil and leucovorin in first-line metastatic colorectal cancer: Results of a randomized phase II trial. J Clin Oncol 23: 3697-3705, 2005.

19. Pinder MC, Duan Z, Goodwin JS, Hortobagyi GN and Giordano SH: Congestive heart failure in older women treated with adjuvant anthracycline chemotherapy for breast cancer. J Clin Oncol 25: 3808-3815, 2007.

20. Muss HB, Woolf S, Berry D, Cirrincione C, Weiss RB, Budman D, Wood WC, Henderson IC, Hudis C, Winer E, et al: Adjuvant chemotherapy in older and younger women with lymph node-positive breast cancer. JAMA 293: 1073-1081, 2005.

21. Fairfield KM, Murray K, Lucas FL, Wierman HR, Earle CC, Trimble EL, Small L and Warren JL: Completion of adjuvant chemotherapy and use of health services for older women with epithelial ovarian cancer. J Clin Oncol 29: 3921-3926, 2011.

22. Sundararajan V, Hershman D, Grann VR, Jacobson JS and Neugut AI: Variations in the use of chemotherapy for elderly patients with advanced ovarian cancer: A population-based study. J Clin Oncol 20: 173-178, 2002.

23. Eisenhauer EL, Tew WP, Levine DA, Lichtman SM, Brown CL, Aghajanian C, Huh J, Barakat RR and Chi DS: Response and outcomes in elderly patients with stages IIIC-IV ovarian cancer receiving platinum-taxane chemotherapy. Gynecol Oncol 106: 381-387, 2007.

24. ten Tije AJ, Verweij J, Carducci MA, Graveland W, Rogers T, Pronk T, Verbruggen MP, Dawkins F and Baker SD: Prospective evaluation of the pharmacokinetics and toxicity profile of docetaxel in the elderly. J Clin Oncol 23: 1070-1077, 2005.

25. Italiano A, Ortholan C, Oudard S, Pouessel D, Gravis G, Beuzeboc P, Bompas E, Fléchon A, Joly F, Ferrero JM and Fizazi K: Docetaxel-based chemotherapy in elderly patients (age 75 and older) with castration-resistant prostate cancer. Eur Urol 55: 1368-1375, 2009.

26. Belani CP and Fossella F: Elderly subgroup analysis of a randomized phase III study of docetaxel plus platinum combinations versus vinorelbine plus cisplatin for first-line treatment of advanced nonsmall cell lung carcinoma (TAX 326). Cancer 104: 2766-2774, 2005 .

27. Fader AN, von Gruenigen V, Gibbons H, Abushahin F, Starks D, Markman M, Belinson J and Rose P: Improved tolerance of primary chemotherapy with reduced-dose carboplatin and paclitaxel in elderly ovarian cancer patients. Gynecol Oncol 109: 33-38, 2008. 